Page, M.L. 'Silences and Disappearing Acts: The Politics of Gendering

Organizational Practice' in Critical management studies at work: Negotiating tensions between theory and practice, J., Wolfram Cox, T. Le Trent-Jones, M., Voronov, and D. Weir, (Eds.). 2009. Cheltenham, UK: Edward Elgar. ISBN 978-184720-400-4.

\title{
15. Silences and disappearing acts: the politics of gendering organizational practice ${ }^{1}$
}

\section{Margaret L. Page}

\section{Overview}

This chapter reflects on the challenges and opportunities of introducing critical frameworks into the practice of promoting gender equality in organizations. It introduces relevant theory and then offers a case study of an action research project, written from the perspective of the researcher. The author tells the story of doing the research and describes the methodology developed. She then reflects on the qualities of critical research methodology and the risks and rewards of sustaining a critical stance in action research. In conclusion she considers the slipperiness of change and difficulty of identifying concrete outcomes. How can critical approaches to conceptualising change and specifically to equalities practice be useful to change practitioners?

\section{Conceptual Framework}

While the rhetoric of equality and diversity as normative culture and practice has been widely absorbed into Western organizations, daily news reports demonstrate that the meanings of both continue to be contested. Policies and practice intended to promote gender equality often thrive alongside organizational practices that reproduce inequality, and may mask wider divisions (Calas and Smircich 1993). As strategies for promoting equality and diversity proliferate it seems particularly timely to explore how current critical organization research might usefully inform them.

The project of gendering organizational analysis is concerned with strategies for interrogating gendered meanings within organizational and management theory (Acker 1990; Mills and Tancred 1992). From this perspective, organizations are sites

\footnotetext{
${ }^{1}$ Full reference:

Page, M. L. 'Silences and disappearing acts: the politics of gendering organizational practice', chapter 15 in Critical Management Studies at Work: Multidisciplinary Approaches to Negotiating Tensions between Theory and Practice Julie Wolfram Cox, Tony G. LeTrent-Jones, Maxim Voronov, David Weir (eds) (2008) New York: Edward Elgar Publishers
} 
for the reproduction and performance of gendered relations, and do not simply reflect gender relations in their external social environments (Gherardi 1995; Meyerson and Kolb 2000). Gendered organizational analysis thus offers a framework for critical research and practice, exploring how management and organization practices in any specific context may reproduce or break patterns of gendered power (Acker, 2000; Ely and Meyerson 2000; Fletcher 1998). It is concerned with gendered assumptions embedded in the ways in which organizations and organizational practices have been theorized, and organizations designed. It has critically interrogated these by drawing from the experiences of women and more latterly from the experiences of men that do not figure within mainstream organizational research. Many of these experiences concern the exercise of power by men over women, and women's strategies of resistance. While these are analysed as instances of systemic gender inequality and injustice, the focus of this research is on individual experiences rather than on collective strategies for promoting equality in organizations.

A separate line of research is specifically concerned with the impact of equality policies and practice within organizations. Within this, a body of research investigates the impact of equal opportunities and diversity policy initiatives on women's inequality in UK public sector organizations. A predominant finding is that while organizational change has altered the ways in which gender relations are expressed, it has not led to any significant shift in the material inequalities between men and women (Breitenbach, Brown, Mackay and Webb 2002; Cockburn 1991; Webb 1997). Yet these researchers note that investigating the reasons for limited impact of the policies and the difficulties in sustaining achievements made has been a source of learning for those involved. One aspect of this learning has been to critically appraise the ways in which change processes that underpin equal opportunities policies and practice have been theorized.

The conjuncture of these two research strands offers the possibility of a different kind of assessment of the experience of doing equalities practice. They are each concerned with different facets of inequality and informed by different visions of change (Calas and Smircich 1996). Some are concerned with strategies to remove structural barriers to women in employment or services (Davidson 1997; Cockburn 1991); some with the intersections of race and gender and local strategies of women managers (Bravette 1996; Bell and Nkomo 1993; Ely, Foldy and Scully 2003; Maddock 1998; Marshall 1995); others with the production of gendered meaning and the performance of gendered leadership in organizations (Collinson and Hearn 1996; hooks 1991; Gherardi 1995; Sinclair 1998; Wajman 1998). All demonstrate the resilience and complexity of gendered and raced power regimes. However postmodern perspectives on organizations offer radical alternatives to linear models of change associated with equal opportunities policy and practice. From these perspectives organizations are sites of difference, conflict, flux, fragmentation and power contestation (Hatch 1997; Linstead, Fulopand Lilley 2004). Gender intersects with other social identities as it is enacted and performed within organizational processes (Acker 2000; Ely et al. 2003).

Assessments of the outcomes of practices designed to improve gender equality in organizations have been predominately negative. Yet this picture, while true, contrasts uneasily with the experiences of complex change processes, the setbacks and achievements that make up the experiences of equalities practitioners of the 80's and 90's (Itzin and Newman 1995; Riley 1990; Scott 2002). Perspectives that engage with 
this complexity seem to offer more potential for understanding the paradoxical nature of changes and setbacks that characterize the experience of doing equal opportunities work in organizations than are offered by the more linear models of change that are embedded in equal opportunities practice and policy. As researchers of equal opportunities note, such perspectives may be helpful, in explaining why planned change is so difficult, and in illuminating the nature of the changes that have been achieved (Coyle 2002).

In the case study that follows, I set out to explore the contrasts and tensions between these different ways of approaching an equal opportunities change initiative. In my analysis I will use a critical framework that offers four frameworks for understanding gender inequality in organizations, each linked to specific change interventions (Meyerson and Kolb 2000). The first two frameworks identify unequal access to opportunities as the cause of women's inequality to men. These are due either to differences in socialization leading to women's skill deficit or to bias leading to gender segregation and blocking women's advancement. Interventions associated with the first framework aim to equip women with skills and in the second to remove discriminatory institutional barriers. The third framework aims to celebrate gender differences rather than to eliminate them. Under this framework, interventions aim to assert the value of diversity to the organization and to empower women and men to challenge cultures and practices that devalue their ways of leading and managing.

Meyerson and Kolb (2000) suggest that while each of these three frameworks has achieved results, none have addressed the practices or the institutional mechanisms through which gender differences are reproduced. They propose a fourth framework in which gender is an axis of power, not located in identity or in discriminatory practices but an organizing principle that shapes apparently gender neutral discourse and organizational practice. This fourth framework is not intended to replace or reject the previous three, but rather to offer a perspective from which to undertake the kinds of interventions they suggest.

This case study tells the story of one attempt to develop an inquiry based change initiative that was informed by a 'frame four' approach.

\section{The case study}

As a consultant and researcher equal opportunities policy and practice had been my bread and butter for many years. Tired of the deficit model on which much equal opportunities practice was based, I determined to develop research that would engage members of organizations as participants and actors, rather than as recipients of training or policy directives. I became interested in the symbolic as an arena for change in its own right, not reducible to structures and processes. I saw that women and men could choose to assert or to subvert given meaning and power dynamics by 'doing gender' differently (Collinson and Hearn 1996; Gherardi 1995). At the same time I became interested in the project of gendering organizational analysis as a framework for relocating equalities practice out of the margins of a specialist arena, as an integral part of generic management practice.

What would an intervention informed by such an approach look like? How could it engage with the way equalities are actually organized? Would it be an intervention in a different territory, using distinctive methods and processes, or would it rather be 
adding a dimension to an existing frame such as perhaps equal opportunities or diversity management?

I set out to create an action research project that would invite participants to explore and challenge how women's leadership was perceived in organizations. Over the following years I found partner organizations, and developed an action research proposal to develop methods for sustaining women in leadership, within their specific contexts. This case study is limited to the project I designed with one of these partner organizations. It was a small part of the wider partnership project which ran over a three year period and was funded by the European Commission.

\section{Surfacing contested agendas}

My partners were equal opportunities advisors within ABC, a local government organization in the UK. In discussion with them a picture emerged of an organization with a progressive reputation for equal opportunities and where excellent policies were in place but not being implemented. They saw the project as an opportunity to push forward initiatives that they had developed and that had met resistance. One of their initiatives was to develop a policy on sexual harassment that had now been introduced. However implementation would require a culture change and it was felt that training and awareness raising would be needed for managers and staff if the policy was to be understood. As I listened to my partners' accounts of seeking to promote equal opportunities for women within a culture that so consistently rewarded traditional forms of masculinity and male power, and women who complied with these traditional forms, I wondered, would it be possible to move out of these embattled zones into inquiry? Could this open up potential for a radical critique of management practice and culture?

In conversation with them, it emerged that 'flash in the pan' high profile new initiatives were endemic. Failure to implement the policies was a symptom of resistance to gender equality, but also a fractal of a wider and more complex pattern of change (Stacey, Griffin and Shaw 2000; Wheatley 1992). While recent reorganization had reduced resources for equal opportunities initiatives, there also seemed to be openings and initiatives underway for positive change. A number of women politicians had recently been elected, including a powerful leader of the council. She was associated with a more participative approach, in contrast to the more traditionally masculine command and control style of leadership associated with the previous regime. In order to explore this picture in all its complexity I proposed an initial phase of open inquiry, in which we would invite women and men in different roles and positions to participate in group discussion to explore their perceptions of women's leadership in the organization. My research partners framed this as an invitation to explore 'barriers to women', and to generate ideas for tackling them. At the end of this phase we agreed to present findings to an open conference, and jointly identify priorities and interventions to pilot.

Through the inquiry groups I hoped to develop collective initiatives for change that would differ from existing equal opportunities practices in two essential respects. Firstly, they would surface and bring more clearly into focus for participants a range of different ways of understanding gendered power in the organization. Secondly, they would enable participants to challenge and rework these representations of gender, in order to 'do gender' differently. This I hoped would locate the construction 
and reproduction of gender inequity as a core dimension of organizational culture and practice. On this basis we might reframe the research from being a special project 'for women' to being a gendered organization development initiative.

Participative action inquiry offered potential for developing an intervention that was both reflexive and collective in intent and design (Coleman and Rippin 2000; Reason and Bradbury 2001). Four inquiry groups were made up of managers (women and men), women employees, women politicians, and members of 'focus groups' for black and minority ethnic, lesbian and gay and disabled employees. These focus groups were referred to in the organization as 'disadvantaged' focus groups, met regularly in work time and had both a support function and management advisory role. About forty women and men took part in the inquiry groups and eighty attended the conference, including the eight most senior managers, all of whom were male. Discussion in the groups was lively and engaged, revealing an organization riven with conflicting values and practices.

The managers' group spoke of having to juggle conflicting sets of expectations, many of which carried gendered associations. For example, a male manager spoke of political injunctions to be a 'listening and learning organization' and the reality of needing to 'blow a power hold to get things done'; in this context he described being alternately facilitative or directive in response to the needs and expectations of teams that he managed. Their discussion evoked an organization in transition, in which desires for a more inclusive, caring, learning organization associated with the new female political leadership were in stark contrast to the need for quick decisions and delivery of results to tight deadlines, associated with the command and control culture of the previous male leadership.

Both the women managers and members of the disadvantaged focus groups expressed a general sense of being devalued and excluded. Some members of the 'disadvantaged' group spoke of providing expert advice to service managers on the needs of their communities, while rewards for improved services went to their managers. Some women described sexualized working environments and unwanted sexual advances by male managers. Others reported negative attitudes towards staff who took up family friendly policies and hostility to women who complained about sexual harassment. Through discussion they explored the disproportionate impact on women of poor management practices, such as reliance on informal networks to access information and inconsistencies in implementation of policies. Some called into question the competence and trustworthiness of women senior managers, who they perceived to be dependent on male patronage and colluding with an abusive management culture. In their narratives women managers were viewed as captives of the male management culture rather than as successful role models. In parallel, they described a culture in which competence of ethnic minority communities and disabled employees was neither seen nor rewarded, associated with 'special' needs, and 'disadvantage' 'rather than with positive assets to the organization.

In contrast, members of the women politicians' inquiry group spoke of the powerful role modelling offered by the leader of the council. They described her as a woman who 'knows the knives are out for her and can handle it'. She inspired them to assert their authority and enabled them to challenge obstruction. They saw her as making legitimate and competent use of her position power, stating that 'she is not on a power 
trip' and 'brings groups together' in contrast to male politicians who preferred to 'keep groups apart' and were 'looking for power'. It seemed that women politicians associated with the new political administration were challenging established narratives and associated practices. Their aspirations for change were invested in the female leader who was attributed with 'male' and 'female' attributes. It seemed that she embodied both the values of a new more inclusive regime and the leadership capacity to face down the old one. Yet stories continued to be told that reproduced the narratives associated with the previous regime. For example the election of the new political leader on her own agenda by a large majority was repeatedly described as an event in which the previous leader 'lost his seat', as if her leadership could be acknowledged only with difficulty.

It seemed that a variety of generative as well as degenerative ways of leading and of managing were associated with women and men, and were already being enacted. However these did not easily find symbolic form or expression within the culture and language of the organization.

\section{Breaking silences and taboos}

A conference was held at which the inquiry groups' findings were reviewed and discussed. 'Barriers' to women were identified concerning general management practice as well as more gender specific issues such as sexual harassment; practical proposals were made for addressing these. Twenty women employees and managers came forward to join the Project Steering Group with a remit to prioritize areas for intervention and develop methods and tools for piloting. The leader of the council and key politicians also pledged their support.

During our early discussions about the rationale for the first phase of the project my clients and I had identified a senior woman manager, previously associated with a leading role in gender equalities work, who might champion the project at a corporate level. We agreed to seek her involvement, but my client had expressed misgivings. Could she be relied upon to act in the project's interest, or would she allow corporate agendas, and her own self-interest, to take priority? She agreed to sponsor the project and to a proposal for a second phase of activity. This was to train Steering Group members to become internal organization consultants. Our purpose was to authorize and accredit their project work and to give them formal status as management advisors.

Steering Group members attended four consultancy days, the first two of which were facilitated as empowerment sessions, the second focussing on change strategy. During the first two days they shared powerful images and metaphors. Asked what strategies they used as protection against being undermined by a powerful (male) manager, some answered, 'Imagine him naked!'

Stripping him of his place in the organization and asserting that managers were after all, only men seemed just retaliation against humiliation. However it did nothing to assert women's position as members of the organization. If women weren't able to subvert the formal authority of male managers, how might they assert their own authority as women within the organization? What would it take for them to feel authorized as leaders of change? During the second two days, Steering Group members drew up an action plan that included an evaluation day to complete the 
Project work. Would they sustain themselves as leaders of change, when many of them saw themselves primarily as outsiders within an alien and predominantly hostile management culture?

In the few months between the consultancy training and the final evaluation day the Steering Group was self organizing, resourced but not led by the senior woman manager. My contact was limited to occasional emails and phone calls. Leadership was offered by a woman politician who had taken part in the inquiry group and who held an organization development role within the political administration. The emergence of this strong political ally authorized and sustained their initiative. Led by her, Steering Group members conducted their own 'road show', a series of the first ever workplace meetings for women employees throughout its many dispersed workplaces. These employees were invited into a further cycle of inquiry, to identify 'barriers to women', and to propose solutions. The Steering Group then put together a report based on their findings and recommendations and took it to corporate management team. Alongside this initiative, some Steering Group members began to take part in 'mainstream' change activities, including the action learning sets run through the Learning Organization program. Around about this time, the first ever sacking of a male manager for sexual harassment took place.

\section{Just another flash in the pan?}

At the end of this phase, the Steering Group organized an open evaluation day to which managers and employees were invited. At this day photographs were taken with key politicians, managers and the local Euro MP, and the event written up in the local press. The research seemed to have been successfully concluded. However, later I heard that through a reshuffle, the politician's organizational development remit was removed. Later still, I heard that the senior woman manager had become critically ill and retired from the organization; and that the equal opportunities manager had left to practice complementary medicine. Was this a metaphor for the impossibility of health for women who try to do gender differently? Had I after all been party to another glossy 'flash in the pan', another high profile initiative with no certain outcomes?

Meyerson and Kolb (2000, p. 566) identify several desirable outcomes of framework four informed research: developing internal change agents who could identify gendering processes that detracted from performance in the organization; identifying concrete changes in work practices that could interrupt these gendering processes; and developing narratives about these processes and outcomes. These proved to be useful categories to consider outcomes achieved in the $\mathrm{ABC}$ project.

\section{Developing internal change agents}

Previous researchers found that collaboration between clients, sponsors and participants was difficult to sustain, and go on to assert that sustaining it is key to a framework four approach (Ely and Meyerson 2000). In ABC the research required a reworking of relationships between women who were differently positioned in the organization, as managers, employees and elected politicians, as well as between women and men. The research methodology offered a container for collaboration to be sustained and repaired breakdowns that occurred (Benjamin 1995). This process was often painful, anxiety provoking and conflictual. The desire for consensus, being 'women together', undermined attempts to offer leadership and there was an over 
dependence on the senior manager despite mistrust of her motives and commitment. This was resolved when the newly elected woman politician took on a leadership role within the research project. Her mobilization of the group to continue the inquiry process, widening participation from women and gathering more data, effectively took the action research method into the organization without competing with equal opportunities practice or relying on leadership from women managers.

Women took up collaborative leadership roles within the organization, asserting a presence in initiatives that were not defined or confined to equal opportunities territory, and confronting the corporate management board with their research findings and proposals. This was not straightforward, and did not lead to guaranteed change outcomes. It did engage participants in acts of resistance and in making proposals for new initiatives, reworking and reinterpreting inhibitors of change.

\section{Interrupting gendering processes and developing new narratives}

Through the project women challenged some of the ways in which inequality was reproduced through organizational processes and then acted collectively to challenge unequal and discriminatory practices. They constructed their own narratives and brought these into the public arena, alongside existing ones.

The inquiry groups and conference did succeed in putting private narratives into the public sphere, asserting the systemic nature of individual experience, and disrupting the boundaries between organizational and personal worlds. Collusion and silences were broken through dialogue between women and men speaking from different organizational roles and positions. In the naming of 'barriers to women' many cultural assumptions and stories about women were challenged, divisions between women were bridged and alliances built. However the language of 'barriers' also reproduced the idea of a potentially neutral organization. Thus while the old narratives were 'interrupted' and spaces created for new ones to emerge, this was not a linear process of development, but something more complex, enacted through processes of conversation, and likely to be characterized by paradox (Shaw 2002; Stacey et al. 2000).

The organizational context was one of power struggle and transitions; a new gender order represented in the female leader of the council had arrived, but predominant language, symbolism and interrelationships continued to assert the old. Equal opportunities policy and practice reproduced the ideal of a benevolent organization whose biases and injustices could be removed through remedial action. On the other hand it offered spaces where members of 'disadvantaged' groups developed narratives and subversive practices that unmasked the myth of equality. Through the project these private narratives were brought into a different more public arena, confronting injustice and asserting a change agenda.

A few men did attend the final evaluation conference and some women present expressed the view that more male participation was needed. This offered potential for male/female alliances to develop and suggested there might be opportunity to explore different ways of being men and managers within the management culture (Collinson and Hearn 1996). 
Framework four envisions gender as an organizing principle that shapes apparently neutral organizational practice, and promotes strategies designed to resist and interrupt the dominant discourse. While this approach did usefully inform the project, results achieved and narratives of how they were achieved were not separate from predominant discourses and practices, but took root from within the spaces they offered. In ABC I have shown that in order to develop framework four strategies the project needed the opportunities offered by the other frameworks to come together, share experience, arrive at new understanding and develop new narratives.

\section{Critical research as change intervention}

For the researcher, sustaining a critical approach required sophisticated relational as well as political and intellectual skills. During my inquiry, powerful images and narratives were voiced. I have shown that these discourses were not simply 'spoken'; they were embodied in relationships between individuals who took up specific subject positions in the project and organization. They had come to represent certain values in the history of the organization, and were characterized as villains, traitors, victims or potential saviours (Gabriel 2004). Powerful projections suffused my relationships with clients, evoking fantasies, thoughts and feelings (Hirschorn 1993). Clients sometimes acted as co- researchers, sometimes as reluctant participants, sometimes as comrades in struggle.

Benjamin describes the inevitability of breakdown of subject to subject relationships. She speaks of the skills of repair that are needed when subject to subject relationships shift into subject to object interactions (Benjamin, 1995). This required critical subjectivity, reflexivity and a capacity to read the psychodynamics and politics of organizational practice (Hirschorn 1993; Reason and Bradbury 2001). During the project I regularly reflected critically on my experience and where possible introduced this into conversations with my co-researchers. It proved essential to have places outside the research to process and make sense of powerful feelings evoked by this work and to test my critical thinking as it evolved.

Inviting others to participate in critical process called into question beliefs and assumptions that were embodied in hierarchical relationships within the organizational culture. In this construction equalities advisors were specialists, making interventions parallel to but separate from other organization change initiatives. My approach invited them to move out of this tried and tested territory, into the more uncertain ground of examining how gender relations were enacted and represented in the context of day to day organizational practice. This created vulnerabilities and risk for participants (Acker 2000). Disagreements arose throughout the project concerning the territory of the research and its desired outcomes and methodology. These were informed by our different readings of what might be possible, in the context of the position and political stance of research sponsors and participants.

Thus disrupting predominant discourses and practices proved to be both fruitful and dangerous. This experience suggests critical researchers will need on the one hand to promote uncertainty of outcome, and on the other hand respect participants' vulnerability and bear the risk of uncertainty themselves. Participatory inquiry seemed to offer a framework for developing a methodology that was flexible, appropriate to 
context and oriented to collaborative change practice. Participants were able to loosen their attachment to narratives associated with binary divisions and to take up more agentic positions from which they developed their own inquiry and narratives of change.

\section{Concluding remarks}

I have shown that new narratives developed alongside the old, and critical frameworks took root within the spaces offered by existing practices. Critical management studies offered a resource from which to reinterpret rather than to replace existing forms of change practice. An important part of the process was to offer spaces through the research process within which participants could explore contested meanings and make these alternative interpretations of events and hidden dimensions of organizational life visible within the organization.

Post-modern perspectives have moved the focus of attention from structures and planned processes of change to ways in which meanings are ascribed and narratives constructed by individuals in organizations. In this case study I have shown that this approach offered ways of engaging with myths and narratives of gendered power within the organization that were not part of the territory of equal opportunities policy and practice. Engaging with the symbolic alongside the material realities of gendered power did offer new dimensions for understanding and for engaging with change and resistance to equalities change initiatives.

It is clear that gender equality is not linear, progressive, or undifferentiated. There are gains and losses, advances and retreats. There can be no blueprint for equality, as the processes through which gendered power is enacted are context specific, and equality the product of struggle and of political agency within each context. In the case study, change outcomes could not easily be identified when viewed through the lens offered by the organization. Yet the critical research stance offered by the researcher, within the framework of a participative research design, had enabled participants to break taboos and silences, and to voice within the public domain dimensions of their experience that had previously been confined to spaces specially designated for the 'disadvantaged'. Collaborative leadership had been taken up by women managers, employees and elected politicians, in order to assert and to demonstrate gendered dimensions of power and inequality within the corporate management domain. In doing so they had disrupted the predominant narratives of equal opportunities. What would be transformed as a result could not be anticipated, and cannot even after the event easily be defined. Rather, the research methodology and stance set a process in motion with its own momentum and limitations. While its effects could not be guaranteed to last in terms of visible outcomes, neither could the acts of collective resistance and their meaning for participants and bystanders be erased.

\section{References}

Acker, J. (1990), 'Hierarchies, jobs, bodies: A theory of gendered organizations', Gender \& Society, 4(2), 139-158.

Acker, J. (2000), 'Gendered contradictions in organizational equity projects', Organization, 7(4), 625-632. 
Bell, E. L and S. M. Nkomo (1992), 'Revisioning women managers' lives', in A. J. Mills and P. Tancred (eds) Gendering Organizational Analysis, London: Sage, pp. 235-247.

Benjamin, J. (1995), Like Subjects, Love Objects: Essays on Recognition and Sexual Difference, New Haven: Yale University Press.

Bravette, G. (1996), 'Reflections on a black woman's management learning', Women in Management Review, 11(3), 3-11.

Breitenbach, E., A. Brown, F. Mackay, and J. Webb, (eds) (2002), The Changing Politics of Gender Equality in Britain, Basingstoke and New York: Palgrave.

Calas, M. and L. Smircich (1996) 'From the woman's point of view: Feminist approaches to organization studies', in S. Clegg, C. Hardy and W.R. Nord (eds) Handbook of Organization Studies, London: Sage, pp. 218-257.

Calas, M. and L. Smircich (1993), 'Dangerous liaisons: the 'feminine- inmanagement' meets 'globalization', Business Horizons, March/April, 71-81.

Cockburn, C. (1991), In The Way of Women: Men's' Resistance to Sex Equality in Organizations, London: Macmillan.

Coleman, G. and A. Rippin (2000), 'Putting feminist theory to work', Organization, 7(4), 573-588.

Collinson, D. L. and J. Hearn (1996), Men as Managers, Managers as Men: Critical Perspectives on Men, Masculinities and Managements, London: Sage.

Coyle, A. (2002), 'Gender politics in the new NHS', in E. Breitenbach, A. Brown, F. Mackay and J. Webb (eds), The Changing Politics of Gender Equality in Britain, Basingstoke and New York: Palgrave, pp. 124-142.

Davidson, M. (1997), The Black and Ethnic Minority Woman Manager, London: Paul Chapman Publishing Ltd.

Ely, R. and Meyerson D. E. (2000), 'Advancing gender equity in organizations: The challenge and importance of maintaining a gender narrative', Organization, 7(4), 589607.

Ely, R. J., E. G. Foldy and M. Scully (eds) (2003), Reader in Gender, Work and Organization, Oxford: Blackwell Publishing.

Fletcher, J. (1998), 'Relational practice: a feminist reconstruction of work', Journal of Management Inquiry, 7(2), 163-186.

Gabriel, Y. (ed.) (2004), Myths, Stories and Organizations, Oxford University Press: Oxford.

Gherardi, S. (1995), Gender, Symbolism and Organizational Cultures, London: Sage. 
Hatch, M. J. (1997), Organization Theory: Modern, Symbolic and Post Modern Perspectives, Oxford: Oxford University Press.

Hirschorn, L. (1993), The Workplace Within, London: MIT Press.

hooks, b. (1991) Yearning: Race, Gender and Cultural Politics, Boston MA:

TurnaroundV

Itzin, C. and J. Newman (eds) (1995), Gender, Culture and Organizational Change, London: Routledge.

Linstead, S., L. Fulop and S. Lilley (2004), Management and Organization: A

Critical Text, Basingstoke and New York: Palgrave Macmillan.

Maddock, S. (1998), Challenging Women: Gender, Culture and Organization, London: Sage Publications.

Marshall, J. (1995) Women Managers Moving On, London: Routledge.

Meyerson, D. E. and D. M. Kolb (2000), 'Moving out of the armchair: Developing a framework to bridge the gap between feminist theory and practice', Organization, 7(4), 553-572.

Mills, A. J., and P. Tancred (1992), Gendering Organizational Analysis, London: Sage Publications.

Reason, P. and H. Bradbury (eds) (2001), Handbook of Action Research, Participative Inquiry and Practice, London: Sage Publications.

Riley, K. (1990) 'Equality for Women - The Role of Local Authorities', Local Government Studies, January/February 1990, 49-67

Scott, M. (2002), 'Women and local government-Dialogue, deliberation and diversity', in E. Breitenbach, A. Brown, F. Mackay, and J. Webb (eds), The Changing Politics of Gender Equality in Britain, Basingstoke and New York: Palgrave, pp. 164177.

Shaw, P. (2002), Changing Conversations in Organizations, London: Routledge.

Sinclair, A. (1998), Doing Leadership Differently: Gender, Power and Sexuality in a Changing Business Culture, Melbourne: Melbourne University Press.

Stacey, R., D. Griffin and P. Shaw (2000), Complexity and Management, Fad or Radical Challenge to Systems Thinking?, London: Routledge.

Wajcman, J. (1998), Managing Like a Man: Women and Men in Corporate Management, Oxford: Polity Press.

Webb, J. (1997) 'The Politics of Equal Opportunity', Gender Work and Organization, 4(3), 159-169 
Wheatley, M. J. (1992), Leadership and the New Science: Learning About Organization from an Orderly Universe, San Francisco: Berret-Koehler 